\title{
Information about COVID-19 for deaf people: an analysis of Youtube videos in Brazilian sign language
}

\author{
Informações sobre COVID-19 para surdos: análise de vídeos do youtube em língua brasileira de sinais \\ Información sobre COVID-19 para sordos: análisis de videos de youtube en lengua de signos brasileña
}

Nelson Miguel Galindo Neto'
ORCID: 0000-0002-7003-165X
Guilherme Guarino de Moura Sá"
ORCID: 0000-0003-3283-2656
Juliana de Castro Nunes Pereira"
ORCID: 0000-0001-6831-1639
Luciana Uchôa Barbosa"
ORCID: 0000-0002-3351-2075
Lívia Moreira Barros'"I
ORCID: 0000-0002-9763-280X
Joselany Áfio Caetano'
ORCID: 0000-0002-0807-056X

'Instituto Federal de Educação, Ciência e Tecnologia de Pernambuco. Pesqueira, Pernambuco, Brazil. "Instituto Federal de Educação, Ciência e Tecnologia de Pernambuco. Belo Jardim, Pernambuco, Brazil. I' Universidade da Integração Internacional da Lusofonia Afro-Brasileira. Redenção, Ceará, Brazil. "Universidade Federal do Ceará. Fortaleza, Ceará, Brazil.

How to cite this article: Galindo Neto NM, Sá GGM, Pereira JCN, Barbosa LU, Barros LM, Caetano JA. Information about COVID-19 for deaf people: an analysis of Youtube videos in Brazilian sign language. Rev Bras Enferm. 2021;74(Suppl 1):e20200291. doi: http://dx.doi.org/10.1590/0034-7167-2020-0291

Corresponding author: Nelson Miguel Galindo Neto E-mail: nelsongalindont@hotmail.com

EDITOR IN CHIEF: Dulce Barbosa ASSOCIATE EDITOR: Italo Rodolfo Silva

Submission: $04-15-2020$

Approval: 09-26-2020

\section{ABSTRACT}

Objective: to analyze YouTube videos with information about COVID-19 in Brazilian sign language. Methods: a cross-sectional study conducted with 402 videos from the YouTube sharing platform. Chi-square, Fisher's exact, Mann-Whitney and Spearman's correlation tests were used. Results: the videos mainly covered COVID-19 prevention (20.6\%). There was a positive correlation between video length and number of views $(p<0.001)$. The length of more than 20 minutes was associated with narration only in BSL $(p=0.37)$ and in BSL with audio $(p<0.001)$, while videos with less than 20 minutes were associated with simultaneous narration in BSL, audio and subtitles. Those with narration only in BSL had a similar number of views to those narrated with subtitles and/or audio ( $p=0.998$ ). Conclusion: the videos were mostly short and included COVID-19 prevention. The longer the video, the greater the number of views. Regardless the presentation of narrations, the videos had a similar number of views. Descriptors: Coronavirus; Sign Language; Persons with Hearing Impairments; Instructional Films and Videos; Health Education.

\section{RESUMO}

Objetivo: analisar vídeos do YouTube com informações sobre COVID-19 em língua brasileira de sinais. Métodos: estudo transversal, com 402 vídeos da plataforma de compartilhamentos YouTube. Foram utilizados testes Qui-Quadrado, Exato de Fisher, Mann-Whitney e Correlação de Spearman. Resultados: os vídeos contemplaram, sobretudo, a prevenção da COVID-19 $(20,6 \%)$. Houve correlação positiva entre duração e número de visualizações do vídeo $(p<0,001)$. A duração superior a 20 minutos se associou à narração somente em Libras $(p=0,37)$ e em Libras com áudio $(p<0,001)$, enquanto vídeos com menos de 20 minutos se associaram com narração simultânea em Libras, áudio e legenda. Aqueles com narração somente em Libras tiveram número de visualizações semelhantes aos narrados com legenda e/ou áudio $(p=0,998)$. Conclusão: os vídeos eram, na maioria, curtos e contemplavam prevenção da COVID-19. Quanto maior a duração do vídeo, maior o número de visualizações. Independente da apresentação das narrações, os vídeos possuíam número de visualizações semelhantes. Descritores: Coronavirus; Línguas de Sinais; Pessoas com Deficiência Auditiva; Filmes e Vídeos Educativos; Educação em Saúde.

\section{RESUMEN}

Objetivo: analizar videos de YouTube con información sobre COVID-19 en lengua de signos brasileña. Métodos: estudio transversal, con 402 videos de la plataforma de intercambio de YouTube. Se utilizaron pruebas de Chi-Cuadrado, Exacta de Fisher, Mann-Whitney y Correlación de Spearman. Resultados: los videos cubrieron principalmente la prevención de COVID-19 $(20,6 \%)$. Hubo una correlación positiva entre la duración y el número de visualizaciones del video $(p<0,001)$. La duración de más de 20 minutos se asoció con la narración solo en lengua de signos $(p=0,37)$ y en lengua de signos con audio $(p<0,001)$, mientras que los videos con menos de 20 minutos se asociaron con la narración simultánea en lengua de signos, audio y subtítulos. Aquellos con narración solo en lengua de signos tuvieron un número de vistas similar a los narrados con subtítulos y/o audio $(\mathrm{p}=0,998)$. Conclusión: los videos fueron en su mayoría cortos e incluyeron la prevención de COVID-19. Cuanto más largo sea el video, mayor será la cantidad de vistas. Independientemente de la presentación de las narraciones, los videos tuvieron un número similar de visualizaciones.

Descriptores: Coronavirus; Lengua de Signos; Personas con Deficiencia Auditiva; Películas y Videos Educativos; Educación en Salud. 


\section{INTRODUCTION}

The disease caused by coronavirus, COVID-19, is an emerging, infectious, highly transmissible, rapidly spreading disease, constituting, since 2020, a public health emergency of international interest ${ }^{(1)}$. According to a report by the World Health Organization (WHO), in May of that year, there were 4,006,257 confirmed cases worldwide and 278,892 deaths due to COVID-19(2). This condition causes respiratory impairment and presents as symptoms: fever, dry cough, difficulty breathing and invasive lung injuries. However, its symptoms may vary according to factors, such as age, comorbidities, lifestyle and may also be asymptomatic ${ }^{(3)}$.

Disease control requires screening and isolation of cases and contacts, mobilization for social distance and individual protection measures, such as hand hygiene, care during sneezing and/or cough and seeking health services, in the face of worsening symptoms, suggestive of COVID-19(4). Thus, the relevance of wide dissemination of information is pointed out, so that the population adopts behaviors that contribute with necessary measures to face the pandemic.

In the context of health communication, the internet provides, for most of the population, an opportunity to access information. Among the possibilities of mass dissemination, the YouTube video sharing platform has a variety of audiovisual content, of amateur and professional origin, which enables and contributes to the dissemination of artistic, communicative and educational content ${ }^{(5)}$. This platform consists of a recognized popular tool, which has already been used to multiply information on disease outbreaks, and, since the end of 2019, has attracted a high audience, specifically because of the COVID-19 outbreak ${ }^{(6)}$.

However, often, the contents disclosed do not include accessibility and are not understandable for some social groups, such as the deaf audience ${ }^{(7)}$. Thus, there is a communication barrier for the access of deaf people to the opportunity for information and knowledge building in health ${ }^{(8)}$. Faced with hearing loss from $40 \mathrm{~dB}^{(9)}$, the deaf population is inserted in a different cultural context, as its form of communication is based on movements, signs and visual stimuli(10-11). In Brazil, deaf people communicate using the Brazilian Sign Language (BSL) ${ }^{(12)}$. For the audience to understand the information, the videos and content published on YouTube must present the narration in that language.

The relevance of videos with content in sign language is ratified. According to WHO, deaf people represent more than 450 million inhabitants in the world, and will reach 900 million by $2050^{(9)}$. As they have a barrier in health communication and, therefore, difficulty in accessing information concerning the prevention of COVID-19, deaf people become vulnerable to constituting a population at risk for viral infection. Thus, the existence of videos in BSL, with information about COVID-19, can contribute to the prevention of harm among deaf people, and with health professionals who, for the most part, do not know how to establish communication in BSL ${ }^{(13)}$.

However, it is worth noting that, in order to direct the construction and publication of videos on YouTube about COVID-19 in BSL, it is necessary to analyze existing videos. Such analysis will enable the gaps in information in sign language, referring to the disease, to be prioritized by future productions.

Among the health professional categories, nursing works at different levels of assistance, has a high possibility of offering care to the deaf population and carries out the health education inherent to their performance ${ }^{(14)}$. Thus, studies that include videos in BSL on COVID-19 are relevant to this professional category, which may use such scientific evidence to support their assistance or contribute to the development of research.

\section{OBJECTIVE}

To analyze YouTube videos with information about COVID-19 in Brazilian sign language.

\section{METHODS}

\section{Ethical aspects}

There was no need for approval by the Research Ethics Committee, since the contents analyzed were in the public domain.

\section{Design, place of study and period}

This is a descriptive, quantitative study, carried out in April 2020, through access to the YouTube video sharing platform (https://www.youtube.com).

\section{Population or sample; inclusion and exclusion criteria}

The population consisted of the videos available/disseminated on that platform. Videos with BSL narration were included. Repeated videos already obtained in the search were excluded. It is noteworthy that the duplicate videos found were counted only once, so that their repetitions were excluded.

\section{Study protocol}

For data extraction, an instrument was used, designed specifically for the present study, which had 13 variables. Of these, three included characteristics of the user page who released/posted the video, called on YouTube, channel: type of channel (personal or institutional), number of subscribers and institution responsible for the channel. The institutions were categorized as public or private education, BSL translation, culture, entertainment, religious, hospital, news agency, Non-Governmental Organization (NGO), Unions, Associations or some health organization (WHO, Ministry of Health and State or Municipal Health Departments).

Moreover, the remaining ten variables addressed the characteristics of the video itself: month and year of posting; narration type ("BSL only", "BSL and audio", "BSL and subtitles" or "BSL, audio and subtitles"); length in seconds; categorization by length of time, according to YouTube criteria, so that the video with a length of less than four minutes, "intermediate", with a length between four and 20 minutes and "long", those with a length greater than 20 minutes; number of views; number of likes and dislikes; character type (human or virtual/avatar) and target audience of the video. It is worth clarifying that, in relation to the target audience, the video that had narration only in BSL was considered aimed at people fluent in that language, and of a universal character (aimed at deaf people and listeners) those who, in addition to BSL, also had narration in audio or subtitles. 
Another information included in the instrument was about the information/content presented by the video. This was analyzed and collected from the contribution of a professional with a BSL Translator and Interpreters, from a federal public educational institution, who has a Bachelor's degree in Linguistics and Languages/BSL, specializing in BSL.

For data collection, the aforementioned platform was accessed, and the search for videos was carried out using the terms "Coronavirus in BSL" and "COVID-19 in BSL". In both searches, video links were organized in a list, for later analysis and data extraction. Such a collection strategy was carried out in order to avoid the non-conformity of the collected data, considering that YouTube allows continuous sharing of videos. It is worth noting that the aforementioned searches were carried out by two researchers, separately, who, after collecting the sample, compared their findings in order to verify possible divergences.

Figure 1 shows the video selection flowchart.

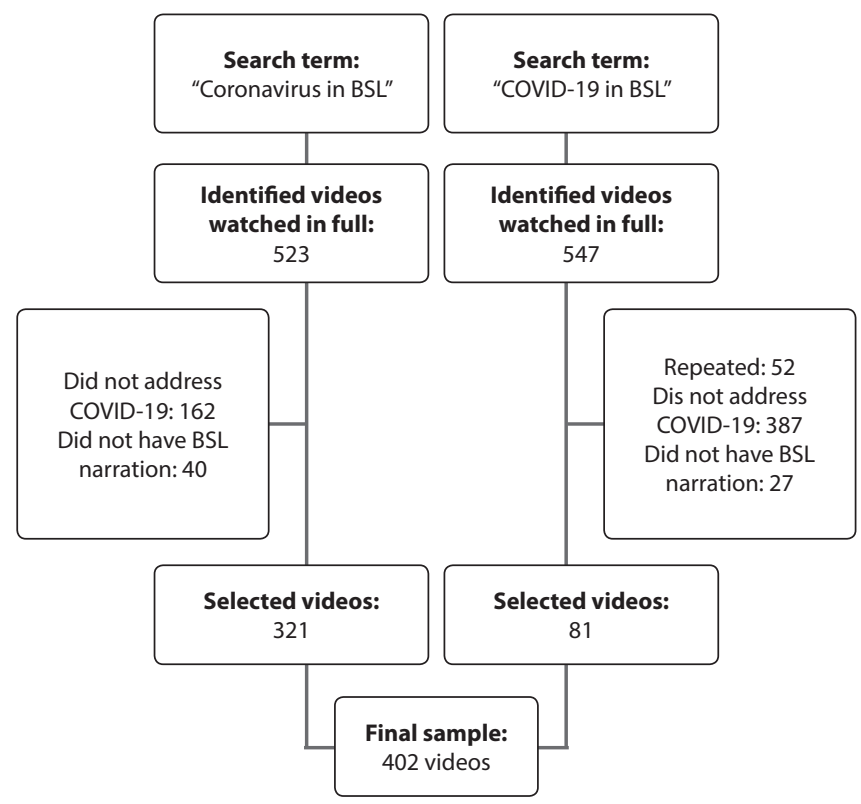

BSL: Brazilian Sign Language.

Figure 1 - Flowchart for selecting YouTube videos with information about COVID-19 in Brazilian Sign Language, Belo Jardim, Pernambuco, Brazil, 2020

\section{Analysis of results, and statistics}

The data were processed by software $R$, version 3.5.1. Categorical variables were described using absolute and relative frequency. The non-adherence to the normality of the numerical variables was found from the Kolmogorov-Smirnov test. Thus, such variables were analyzed from the median, as a measure of central tendency, and Interquartile Range (IR), as a measure of dispersion. The association between video length and types of narration was verified using Pearson's Chi-Square Test and Fisher's Exact Test. The medians of video views were compared using the Mann-Whitney test, and the correlation between video length and number of views was verified using Spearman's coefficient. To identify and order the magnitude of the correlations, the values of the correlations below 0.30 were considered as weak, between 0.30 and 0.50 , moderate and, above 0.50 , strong ${ }^{(15)}$.
For all tests, a significance level of $5 \%$ and a $95 \%$ confidence index were adopted.

\section{RESULTS}

The 402 videos included in the sample were published in 2020. Of these, 11 (2.7\%) were released in January, 14 (3.5\%) in February, 291 (72.4\%) in March and 86 (21.4\%), in April.

Concerning video length, 289 (71.9\%) were classified as short, 100 (24.9\%), as intermediate and 13 (3.2\%), as long. With regard to dissemination channels, $260(64.7 \%)$ were posted on individual channels and 142 (35.3\%) on institutional channels, as detailed in Table 1.

Table 1 - Video length about COVID-19 in Brazilian Sign Language, according to the type of channel on which it was posted, Belo Jardim, Pernambuco, Brazil, 2020

\begin{tabular}{lcccc}
\hline & \multicolumn{3}{c}{ Video length } & Total \\
Post channel type & $\begin{array}{c}\text { Short } \\
\mathbf{n}(\%)\end{array}$ & $\begin{array}{c}\text { Intermediate } \\
\mathbf{n}(\%)\end{array}$ & $\mathbf{n}(\%)$ & $\mathbf{n}(\%)$ \\
\hline Natural/legal person & $185(46.0)$ & $68(16.9)$ & $7(1.7)$ & $260(64.7)$ \\
& & & & \\
Public education & $61(15.2)$ & $17(4.2)$ & $0(0.0)$ & $78(19.4)$ \\
News agencies & $20(5.0)$ & $5(1.2)$ & $5(1.2)$ & $30(7.5)$ \\
Religious Institution & $2(0.5)$ & $6(1.5)$ & $0(0.0)$ & $8(2.0)$ \\
State Health Departments & $5(1.2)$ & $0(0.0)$ & $1(0.2)$ & $6(1.5)$ \\
NGOs/Unions/Associations & $1(0.2)$ & $4(1.0)$ & $0(0.0)$ & $5(1.2)$ \\
Private education & $3(0.7)$ & $0(0.0)$ & $0(0.0)$ & $3(0.7)$ \\
BSL Translation Company & $3(0.7)$ & $0(0.0)$ & $0(0.0)$ & $3(0.7)$ \\
Ministry of Health & $2(0.5)$ & $0(0.0)$ & $0(0.0)$ & $2(0.5)$ \\
Municipal Health & $2(0.5)$ & $0(0.0)$ & $0(0.0)$ & $2(0.5)$ \\
Departments & & & & \\
Entertainment Institution & $2(0.5)$ & $0(0.0)$ & $0(0.0)$ & $2(0.5)$ \\
Culture Institution & $2(0.5)$ & $0(0.0)$ & $0(0.0)$ & $2(0.5)$ \\
Municipal Department of & $1(0.2)$ & $0(0.0)$ & $0(0.0)$ & $1(0.2)$ \\
Education & & & & \\
Total & $289(71.9)$ & $100(24.9)$ & $13(3.2)$ & $402(100.0)$ \\
& & & &
\end{tabular}

The median number of people subscribed to the channels was 170.5 (IR=29.7 - 1070), the video length was 141 seconds $(I R=69.7-262.2)$, and the number of views was $60,5(I R=17-279.6)$. Although most videos are short, there was a positive correlation, of low magnitude and statistically significant $(r=0.270 ; p<0.001)$ between video length and number of views, so that the greater the video length, the greater the number of views.

Concerning the narration present in the video, it was observed that 147 (36.6\%) had the content narrated exclusively in BSL, 143 (35.6\%) had narration in BSL and audio, 80 (19.9\%) had narration in BSL and subtitles and 32 (8.0\%) had the three possibilities of narration presented simultaneously (BSL, audio and subtitles). Videos longer than 20 minutes (long) were associated with the presentation of narration only in BSL $(p=0.37)$ and in BSL with audio ( $p<0.001)$, while those with less than 20 minutes (short and intermediate) were associated with the narration presented in the three narration forms, BSL, audio and subtitles (Table 2). 
Table 2 - Association of video length with the types of narration used, Belo Jardim, Pernambuco, Brazil, 2020

\begin{tabular}{lccccccc}
\hline & \multicolumn{7}{c}{ Video length } \\
Narration & $\begin{array}{c}\text { Short } \\
\text { Intermediate }\end{array}$ & \multicolumn{2}{c}{ Long } \\
& $\mathbf{n}(\%)$ & $\boldsymbol{p}$ & $\mathbf{n}(\%)$ & $\boldsymbol{p}$ & $\mathbf{n}(\%)$ & $\boldsymbol{p}$ \\
\hline BSL & $102(69.4)$ & $0.397^{*}$ & $44(29.9)$ & $0.075^{*}$ & $1(0.7)$ & $0.037^{* *}$ \\
BSL and subtitle & $60(75.0)$ & $0.489^{*}$ & $20(25.0)$ & $0.977^{*}$ & $0(0.0)$ & $0.080^{* *}$ \\
BSL and audio & $97(67.8)$ & $0.179^{*}$ & $34(23.8)$ & $0.705^{*}$ & $12(8.4)$ & $<0.001^{* *}$ \\
BSL, subtitle and & $30(93.8)$ & $0.004^{*}$ & $2(6.2)$ & $0.009^{* *}$ & $0(0.0)$ & $0.611^{* *}$ \\
audio & & & & & & \\
\hline Note: ${ }^{*}$ Chi-Square; **Fischer's exact; BSL: Brazilian Sign Language.
\end{tabular}

From the types of narration used in the videos, it was observed that 245 (60.9\%) videos enabled understanding of deaf people and listeners, because they have another narration resource (subtitle and/or audio) besides BSL, while 157 (39.1\%) videos made it possible to understand only people fluent in BSL, since their narration was presented, exclusively, in sign language. Videos with narration only in BSL had similar number of views to those that had another narration feature (subtitle and/or audio) ( $p=0.998)$.

Likes had a median of $5(\mathrm{IR}=1$ - 19) and dislikes, a median of 0 $(\mathrm{I}=0$ - 0). Concerning video content, 23 subtopics were found, so that the largest number of videos addressed the prevention and explanations of general information (definition, form of transmission, symptoms, prevention and treatment) of COVID-19. The number of videos, by subtopic, as well as the medians of likes, dislikes and views, is detailed in Table 3.

Concerning the type of character, 391 (97.3\%) videos were produced from capturing the image of real people, while 11 $(2.7 \%)$ were produced using virtual characters/avatar.

\section{DISCUSSION}

Most of the videos in BSL, referring to COVID-19, were posted on individual channels. This finding differs from a study that investigated YouTube videos on diabetic foot, which found only $8.3 \%$ of posts coming from these channels ${ }^{(16)}$. The fact that the content in BSL has been disseminated on personal channels points to the recent need of institutions, in their communication channels, to disseminate content in a manner compatible with the understanding of the people who communicate through BSL. This context shows the engagement of the population sensitized by the cause of inclusion, in disseminating the contents in sign language. Thus, it is pertinent that nurses who work in institutions that disseminate their health content in the form of videos add the narration in BSL in such productions, with a view to corroborating the translation of the knowledge of the deaf public, in the different communication channels.

Still with regard to the channels on which the videos were released, it was observed that, among those that came from institutional pages, there was a greater amount of videos posted on channels belonging to public education agencies. This fact corroborates what was found in a study carried out in Spain, with YouTube videos for adolescents, whose results also showed a majority of posts coming from public institutions ${ }^{(5)}$. Thus, it is relevant to point out and recognize that these institutions have proved to be exemplary, with social commitment and a leading role in the dissemination of materials that contribute to health education. It also points out the viability of nurses who act as educators in such public educational institutions to raise the disclosure of their participation in the construction of the content to be presented in BSL.

It was observed that most videos were published in March 2020. It is understandable the absence of material available in the period prior to the referred month and year. COVID-19 transmission occurred in China in late 2019, and the disease became a public health emergency and characterized a pandemic in February $2020^{(17)}$. It should be noted that the first confirmed case of the disease, in Brazil, occurred at the end of February. Moreover, January and February generally have an atypical routine in Brazil, due to the existence of school breaks and carnival, which, added to the time required for video production, may justify the small amount of material posted in these months.

Concerning length, most of the videos were short (less than four minutes). Thus, there is little difference in video length in BSL, when compared to other videos referring to health topics, without content in BSL, as observed in two studies conducted in the United States. The first found a median of 5.53 minutes in videos on autism ${ }^{(18)}$ and the second showed a median of 6.32 in videos on dementia ${ }^{(19)}$. 
The most contemplated subtopic in BSL videos was the prevention of COVID-19. It is pointed out that this subtopic is present in the health content, given its clinical importance and because it is a spectrum of action and popular leading role, which should be the target of intense dissemination. Accordingly, it is observed that prevention was also the most explored aspect in YouTube videos in Spanish about sex, bullying, drugs and adolescent pregnancy ${ }^{(5)}$. The preventive approach understandable by the deaf population is relevant, since as science seeks evidence about the transmission, clinical aspects, diagnosis and treatment of COVID-19, prevention is the fastest, most effective and feasible action to reduce transmissibility and, therefore, mortality, as an example of success in China, the epicenter of the pandemic ${ }^{(20)}$.

The videos about COVID-19 in BSL had a median of 60.5 views, lower than that found in a study on YouTube videos about medical procedure, which had 150 thousand to 350 thousand accesses ${ }^{(21)}$. The difference in such views can be justified, since the search for content on the internet varies according to the interest in the subject ${ }^{(5)}$, so that BSL videos are attractive to a restricted audience of people who understand sign language. Furthermore, the intense dissemination by the media about content related to COVID-19, may have reduced the need to search for such content on YouTube, which resulted in reduced views.

In relation to the views, a positive association was observed between them and the video length, which corroborates what was found in a study referring to YouTube videos on histology, which also found a greater number of accesses in longer videos ${ }^{(22)}$. Such findings may result from the possible presence of more information in the larger videos, which may influence the interest in viewing. Thus, it is pertinent that nursing, as a health educator and, therefore, a professional category capable of contributing to the construction of videos in BSL, considers the most complete and least fragmented offer of information, in an attempt to reach a greater number of views.

Concerning the types of narration, the videos narrated only in BSL predominated and those that were narrated, simultaneously, in BSL and audio. The lesser use of subtitles is relevant, as the textual understanding of deaf people is not the same as that of listeners. Although there are literate deaf people, depending on the size and form of writing the text, it is common to have difficulty understanding, so the use of subtitles, in videos for deaf people, should occur with caution ${ }^{(23)}$. This context is corroborated by a study carried out in Malaysia, in which deaf people participated in the creation of an application, demonstrating that they do not prefer the presence of texts in the presentation of the content of the technology ${ }^{(24)}$. Thus, it is pointed out that nursing should consider this aspect, and not prioritize the use of subtitles/written content in the construction of educational materials for deaf people.

Concerning length and narrations, long videos were associated with two types of narration: only in BSL and simultaneous in BSL and audio. Short and intermediate videos were associated with the presence of narration with simultaneous BSL resources, audio and subtitles. Such findings may be related to the need for structural investment to narrate the content of a video in the three possible ways (BSL, audio and subtitles), so that this triple narration becomes more likely to be carried out in videos of shorter length, being more expensive in longer videos.
It should be noted that the results of the study presented two information that are complemented in the clinical logic: the first is that the longer videos had more views; the second is that the longer videos were also associated with the presence of BSL narration and audio, concurrently. Thus, it is possible that these longer videos, which did not have narration only in BSL, but also in audio, were also seen by listeners, which would justify the association of the videos being long with the fact that they are seen more.

It was observed that, regardless whether they present narration only in BSL or simultaneous with subtitles and/or audio, the videos had a similar amount of views. In this context, it is pointed out that all the analyzed videos had narration in BSL. Thus, they could be the target of the interest of deaf people, regardless the concomitant existence of another type of narration. Furthermore, it is necessary to consider that the content of videos are not restricted to access by deaf people, but may have been viewed by interpreters and teachers, as observed in a study that analyzed the speech of deaf people teachers and listeners and whose results showed that they also use YouTube resources in the communication and teaching-learning process ${ }^{(25)}$.

\section{Study limitations}

As a limitation of this study, the analysis restricted to videos with narration in sign language from Brazil is pointed out, so that the data found may differ from the reality of videos with sign language from other countries.

\section{Contributions to nursing, health, and public policies}

The findings presented contribute to the state of the art about health education related to COVID-19, aimed at a specific audience and little addressed in research on health communication, deaf people. This study points out relevant questions about access to health information, which corroborate public policies concerning accessibility and inclusion. Moreover, the results found contribute to the professional practice of nursing, which can use this scientific support to direct the production of new videos about COVID-19 in BSL. Their findings can support nurses in the construction of new audiovisual materials, aimed at deaf people, pertinent to be submitted to the content and appearance validation process. Furthermore, it can awaken nursing to prioritize the use and sharing of materials with narration in BSL, to the detriment of those with narration only in audio, in order to contribute to the multiplication of access to information in the deaf community.

\section{CONCLUSION}

Analysis of YouTube videos with information about COVID-19 in BSL allowed us to conclude that the main channels for the dissemination of videos were for individuals, the most contemplated subtopic in the videos was the prevention of COVID-19, most of the videos had length less than four minutes, with a median of 60.5 views. There was a positive correlation between video length and number of views. The length of more than 20 minutes was associated with narration only in BSL and BSL with 
audio, while videos with less than 20 minutes were associated with narration presented simultaneously in BSL, audio and subtitles. Videos with narration only in BSL had a similar number of views to those that had another narration feature (subtitle and/or audio). Moreover, most of videos were produced from capturing real people images.
It is recommended that future studies investigate quantitative aspects related to satisfaction, understanding and change in knowledge and behavior, provided to deaf people by YouTube videos, as well as investigating the quality of existing videos. Furthermore, it is pertinent to unveil subjective issues with deaf people about the experience and opinion about the videos.

\section{REFERENCES}

1. Morens DM, Daszak P, Taubenberger JK. Escaping Pandora's Box-Another Novel Coronavirus. N Engl J Med. 2020;382:1293-1295. doi: 10.1056/NEJMp2002106

2. World Health Organization (WHO). Cononavirus disease (COVID-19) Situation Report - 112. World Health Organization [Internet]. 2020 [cited 2020 Apr 13]. Available from: https://www.who.int/docs/default-source/coronaviruse/situation-reports/20200511-COVID-19sitrep-112.pdf?sfvrsn=813f2669_2

3. Toit AD. Outbreak of a novel coronavirus. Nat Rev Microbiol. 2020; 18: 123. doi: 10.1038/s41579-020-0332-0

4. Lipsitch M, Swerdlow DL, Finelli L. Defining the Epidemiology of COVID-19 - Studies Needed. N Engl J Med. 2020; 382:1194-6. doi: 10.1056/ NEJMp2002125

5. Jiménez AG, Vozmediano MM. Subject matter of videos for teens on YouTube. Intern J Adolesc Youth. 2020;25(1):63-78. doi: $10.1080 / 02673843.2019 .1590850$

6. Khatri P, Singh SR, Belani NK, Yeong YL, Lohan R, Lim YW, et al. YouTube as source of information on 2019 novel coronavirus outbreak: a cross sectional study of English and Mandarin content. Trav Med Infec Disease. 2020;35:101636. doi: 10.1016/j.tmaid.2020.101636

7. Santos AS, Portes AJF. Perceptions of deaf subjects about communication in Primary Health Care. Rev Latino-Am Enfermagem. 2019;27:e3127. doi: 10.1590/1518-8345.2612.3127

8. Naseribooriabadi T, Sadoughi F, Sheikhtaheri A. Barriers and facilitators of health literacy among d/deaf individuals: a review article. Irã J Saúde Pública [Internet]. 2017 [cited 2020 Jan 18];46(11):1465-1474. Available from: https://www.ncbi.nlm.nih.gov/pmc/articles/PMC5696685/

9. World Health Organization (WHO). Deafness and hearing loss [Internet]. 2018 [cited 2020 Jan 16]. Available from: http://www.who.int/ news-room/fact-sheets/detail/deafness-and-hearing-loss

10. Galindo-Neto NM, Lima MB, Barros LM, Santos SC, Caetano JÁ. Sing language instrument for assessing the knowledge of deaf people about Cardiopulmonary Resuscitation. Rev Latino-Am Enfermagem. 2020;28:e3283. doi: 10.1590/1518-8345.3535.3283

11. Beltrami CM, Moura MC. The deaf education in the inclusion process in Brazil in the last 50 years (1961-2011). REB [Internet]. 2015 [cited 2020 Apr 13];8(1):146-161. Available from: https://revistas.pucsp.br/reb/article/view/19930

12. Chininthorn P, Glaser M, Tucker WD, Diehl JC. Exploration of deaf people's health information sources and techniques for information delivery in cape town: a qualitative study for the design and development of a mobile health app. JMIR Hum Factors. 2016;3(2):e28. doi: 10.2196/humanfactors.6653

13. Zander M. Public health and disability studies. Public Health Forum. 2017;25(4):259-61. doi: 10.1515/pubhef-2017-0041

14. Galindo-Neto NM, Alexandre ACS, Barros LM, Sá GGM, Carvalho KM, Caetano JÁ. Creation and validation of an educational video for deaf people about cardiopulmonary resuscitation. Rev Latino-Am Enfermagem. 2019;27:e3130. doi: 10.1590/1518-8345.2765.3130

15. Ajzen I, Fishbein M. Understanding attitudes and predicting social behaviour. Englewood Cliffs, New Jersey: Prentice Hall; 1980.

16. Silva E, Toledo MM, Tolomeu JSO, Nominato GA, Nunes APN, Castilho LF. Are YouTube Portuguese videos useful as a source of information on diabetes foot care? Braz J Develop.2020;6(1):1305-12. doi: 10.34117/bjdv6n1-091

17. Jiang F, Deng L, Zhang L, Cai Y, Cheung CW, Xia Z. Review of the Clinical Characteristics of Coronavirus Disease 2019 (COVID-19). J Gener Intern Med. 2020;35:1545-9. doi: 10.1007/s11606-020-05762-W

18. Bellon-Harn ML, Manchaiah V, Morris LR. A cross-sectional descriptive analysis of portrayal of autism spectrum disorders in YouTube videos: a short report. Autism. 2019;24(1):263-8. doi: 10.1177/1362361319864222

19. Lam NHT, Woo BKP. YouTube as a new medium for dementia education among Chinese Americans. Com Mental Health J. 2020;56:435-9. doi: 10.1007/s10597-019-00493-7

20. Cascella M, Rajnik M, Cuomo A, Dulebohn SC, Di Napoli R. Features, evaluation and treatment Coronavirus (COVID-19). StatPearls [Internet]. Treasure Island (FL). 2020 [cited 2020 Apr 13]. Available from: https://www.ncbi.nlm.nih.gov/pubmed/32150360

21. King D, Davison D, Heinz, E, Vaziri K, Yamane D. 1026: Using YouTube videos to teach central lines: does it make the cut? Crit Car Med. 2020; 48 (1):492. doi: 10.1097/01.ccm.0000643040.36581.89

22. Souza CFL, Ferreira JM, Pereira AC, Silva MAD. Understanding the use of videos as a complementary teaching tool. J Health Inform [Internet]. 2019 [cited 2020 Apr 13];11(1):3-7. Available from; http://www.jhi-sbis.saude.ws/ojs-jhi/index.php/jhi-sbis/article/view/600/348 
23. Galindo Neto NM, Áfio ACE, Leite SS, Silva MG, Pagliuca LMF, Caetano JÁ. Technologies for health education for the deaf: integrative review. Texto Contexto Enferm. 2019;28:e20180221. doi: 10.1590/1980-265X-TCE-2018-0221

24. Jacob SA, Yen-Chuen CE, Goh SL, Palanisamy UD. Design suggestions for an mHealth app to facilitate communication between pharmacists and the deaf: perspective of the deaf community (HEARD Project). mHeath. 2020. doi: 10.21037/mhealth.2020.01.04

25. Xavier MB, Carvalho FS, Carvalho MS, Moraes JM. Deaf identity: an analysis of the discourses of deaf teachers and listeners on Youtube. Id onLine Rev Mult Psic [Internet]. 20192020 [cited 2020 Apr 13];13(45):331-40. Available from: https://idonline.emnuvens.com.br/id/article/ view/1719/2517 